\title{
The Impact of Applying the Blue Ocean Strategy on the Achievement of a Competitive Advantage: A Field Study Conducted in the Jordanian Telecommunication Companies
}

\author{
Mohammad Ali Al Qudah ${ }^{1}$, Tareq N. Hashem ${ }^{2}$ \\ ${ }^{1}$ Police Science Academy in Sharjah, United Arab Emirates \\ ${ }^{2}$ Associate Professor, Marketing Department, Isra University, Amman. Jordan \\ Correspondence: Tareq N. Hashem, Associate Professor, Marketing Department, Isra University, Amman - \\ Jordan.
}

Received: July 26, 2018

doi:10.5539/ibr.v11n9p108

\begin{abstract}
The present study aimed to identify the impact of applying the blue ocean strategy on the achievement of a competitive advantage in the Jordanian telecommunication companies. In order to achieve the study's objectives, the descriptive analytical approach was adopted and a questionnaire was developed. After that, the questionnaire forms were distributed to the selected sample. The sample consists of one hundred (100) administrators working in Jordanian telecommunication companies. The researchers used descriptive statistical methods, as well as, linear regression analysis, that were done to test the study's hypotheses and analyze the collected data. Several results were concluded. For instance, it was concluded that the blue ocean strategy dimensions are highly applied. It was also found that the elimination process significantly affects the achievement of a competitive advantage. It was also found that the reduction process significantly affects the achievement of a competitive advantage. In addition, it was found that the increasing process significantly affects the achievement of a competitive advantage. It was found that the innovation process significantly affects the achievement of a competitive advantage. In the light of the aforementioned results, several recommendations were suggested by the researchers. For instance, the researchers recommend providing customers with service guarantees by the Jordanian telecommunication companies. In addition, the researchers recommend overcoming the obstacles that hinder the application of the blue ocean strategy by the senior management. The researchers recommend utilizing the blue ocean strategy by companies and avoiding negative competition. The researchers also recommend making significant strategic changes in an ongoing manner. Such changes should be provided with support by the board of directors.
\end{abstract}

Keywords: The blue ocean strategy, elimination, innovation, raising, reduction, competitive advantage

\section{Introduction}

The (blue ocean strategy) is considered a modern expression in the business field. The latter strategy is adopted by companies for marketing their products and avoiding negative competition. It is based on creating blue oceans rather than creating red oceans. That is done through seeking to create an uncontested market place rather than competing within the existing market place. The latter strategy is usually adopted by the leading companies. When seeking to create an uncontested market place, the competition shall be irrelevant. Thus, prospects for growth shall be high.

One of the key principles of the latter strategy is the (value innovation) principle. Adopting the latter principle shall raise the company's value and provide customers with a value. That shall leave competitors helpless. Through the blue ocean strategy, a new demand shall be created by the company. There shall be also uncontested markets created in which the competition is irrelevant. In the latter markets, there shall be no bloody conflicts between companies. In fact, the company shall excel without experiencing a conflict its other competitors. Today, there is an intensive competition between companies. In the light of such a competition, it became harder for companies to gain profits, grow, succeed and outperform their competitors. It also became harder for companies to obtain a greater market share. Thus, it became harder for leading companies to maintain their performance level. Hence, companies today are in need for adopting new approaches and strategies that enable them to 
become distinguished and leading companies. Adopting such approaches and strategies shall enable companies to maintain their position in the market.

Through the blue ocean strategy, the competition shall be irrelevant and several strategic tools shall be used for creating blue oceans. In addition, the latter strategy involves designing an analytical structure by a creative person. The effectiveness of the structure shall be tested before adopting it.

\section{Statement of the Problem}

Today, there is an intensive competition between companies. In addition, the supply is greater than demand. Companies need to succeed and develop. They also need to search for markets that do not include competitors. There is also an intensive competition between the Jordanian telecommunication companies. Therefore, the present study aimed to explore the impact of applying the blue ocean strategy on the achievement of a competitive advantage in the Jordanian telecommunication companies. The researchers aimed to explore that in the light of the recommendations provided by Hashem \& Joudeh (2017) which emphasized the importance of using the blue ocean in business organizations.

\section{The Study's Questions}

Through the present study, the researchers aimed to answer the following questions:

Q.1) Is there any statistically significant relationship between applying the blue ocean strategy and the achievement of a competitive advantage in the Jordanian telecommunication companies?

Q.2) Is there any statistically significant relationship between applying the blue ocean strategy dimensions(the elimination process, the reduction process, the increasing process, the innovation process ) and the achievement of a competitive advantage in the Jordanian telecommunication companies?

\section{The Study's Significance}

The present study is considered significant due to the following reasons:

1) Today, companies are highly in need for achieving success and a competitive advantage. That is needed to ensure survival and generate profits. Hence, the present study helps companies in achieving a competitive advantage.

2) It is highly necessary to explore the relationship between the application of the blue ocean strategy and the achievement of a competitive advantage. That is necessary because the competitive advantage is a significant indicator for identifying an organization's success.

3) In case the blue ocean strategy proved its effectiveness through studies, it shall be utilized by companies for achieving success and growth. That shall enable companies to win the competition.

\section{The Study's Objectives}

The present study aimed at:

1) Identifying the impact of applying the blue ocean strategy on the achievement of a competitive advantage in the Jordanian telecommunication companies.

2) Identifying the impact of the blue ocean strategy dimensions jointly and separately on the achievement of a competitive advantage in the Jordanian telecommunication companies.

3) Suggesting several recommendations which may be useful for researchers, administrators, and policy makers in business organizations. 


\section{The Study's Model}

Independent Variable

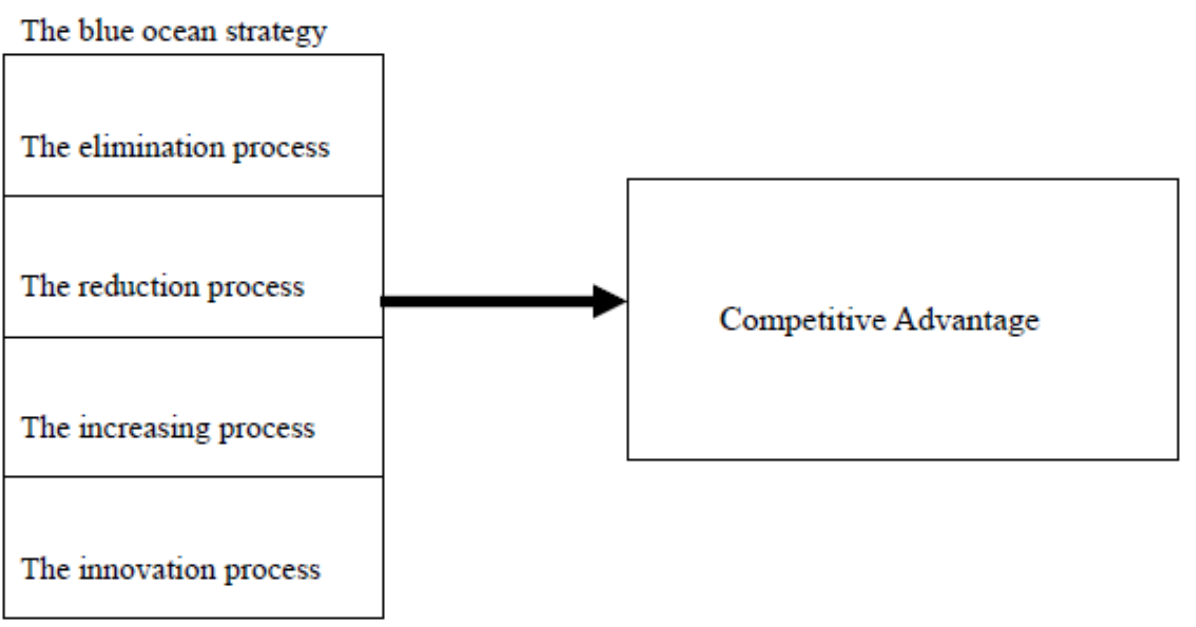

Source: (Hashem \&Joudeh, 2017)

\section{The Study's Hypotheses}

The Main Hypothesis:

H0.1: The blue ocean strategy dimensions jointly do not have any statistically significant impact on the achievement of a competitive advantage in the Jordanian telecommunication companies

The Sub- Hypotheses

H0.1.1: The elimination process - which is a blue ocean strategy dimension - doesn't have any statistically significant impact on the achievement of a competitive advantage in the Jordanian telecommunication companies

H0.1.2: The reduction process - which is a blue ocean strategy dimension - doesn't have any statistically significant impact on the achievement of a competitive advantage in the Jordanian telecommunication companies

H0.1.3: The increasing process - which is a blue ocean strategy dimension - doesn't have any statistically significant impact on the achievement of a competitive advantage in the Jordanian telecommunication companies

H0.1.4: The innovation process - which is a blue ocean strategy dimension - doesn't have any statistically significant impact on the achievement of a competitive advantage in the Jordanian telecommunication companies

\section{The Theoretical Framework}

The meaning of the Blue Ocean Strategy

According to Kim and Mauborgne (2005), the blue ocean strategy enables companies to achieve their goals and apply their strategies. Through the latter strategy, customers are provided with value and good offers. In contrast to the red ocean strategy, the blue ocean strategy makes the competition irrelevant. It aims to achieve differentiation and low cost simultaneously. It also aims to create an uncontested market place that companies can't compete in. In addition, it aims to break the value cost trade off. It aims at aligning the company's activities in accordance with the cost reduction strategy. That should be done to achieve differentiation.

The expression (blue ocean strategy) is a new expression in the business management field in general and the marketing management field in particular. It is called so because it aims to eliminate the intensive competition in which competitors fight with each other for the same thing. Through such fight, competitors turn the market place into a bloody battlefield. Thus, eliminating the competition shall make the market place similar to a clear blue water that doesn't include bloody sharks fighting for the same pray. As for the red ocean strategy, it includes a market place that is full of competitors. Such a market place is similar to an ocean full of bloody sharks that keep fighting one another to get the same prey. Such fight shall turn the water bloody.

It should be noted that scholars have provided different definitions for the expression (blue ocean strategy). Such definitions differ due to the difference between scholars in terms of orientations and ideologies. Some of those definitions are presented in table 1 below: 
Table 1. Some of the definitions of the expression (blue ocean strategy)

\begin{tabular}{lll}
\hline No. Source & Definition \\
\hline $1 \quad$ Kim \& Mauborgne (2005) & $\begin{array}{l}\text { This strategy aims to create a new market place which hasn't been discovered by } \\
\text { anyone nor any competitor before. In the new market, the company shall not have } \\
\text { any one to compete with. Thus, the competition shall be irrelevant. That is because } \\
\text { the rules of the game haven't been set yet. }\end{array}$ \\
2 Armstrong \& Kotler (2007) & $\begin{array}{l}\text { Through applying this strategy, a company aims to understand and identify } \\
\text { customers' needs and desires. It also aims to develop a strategy in accordance with } \\
\text { those needs and desires. It aims to provide customers with a value and build good } \\
\text { relationships with them. It also aims to achieve all of that without having to } \\
\text { compete with others. }\end{array}$ \\
3 & $\begin{array}{l}\text { Through applying this strategy, a company aims to go beyond the existing industry } \\
\text { boundaries. It also aims to create a new market place to sell products without } \\
\text { competing with others }\end{array}$ \\
& $\begin{array}{l}\text { Through applying this strategy, a company aims to create a new uncontested } \\
\text { market place and avoid competing with others. }\end{array}$
\end{tabular}

Yang (2007) believes that applying the blue ocean strategy means that a company must search for a new uncontested market place. Such a market place must be unknown by competitors in order to create a new demand. That shall enable the company to find new investment opportunities. Through such opportunities, the company can ensure survival, achieve growth and gain profits. In other words, applying the blue ocean strategy means that the company must produce something that hasn't been produced before anyone else. It also means that the company must adapt itself for fulfilling the customers' needs and desires.

In fact, there are many reasons that make companies in need for applying the blue ocean strategy. Such reasons may include the following (Kim \& Maubrogne, 2005, p.4):

1) The technologies used for industrial production have been developing rapidly

2) The numbers of industries have been increasing and the supply exceeds the demand.

3) Suppliers are allowed to produce different types of services and products which haven't been produced before.

4) Shifting towards globalization. That is represented in the globalization of markets, and the automatic exchange of information. In addition, technological advancements have been spreading quickly.

5) It is difficult to predict the economic fluctuations that shall occur in the international business environment. It is also difficult to predict any change that may be made to the social and environmental legislations.

\section{Dimensions of Blue Ocean Strategy:}

The following is a brief explanation of each of these dimensions, which will be the cornerstone of adopting the Blue Ocean Strategy:

- Elimination process: Business organizations exclude some elements they deem unnecessary in their work, reducing costs to a minimum, without affecting sales and quality levels.

- Reduction process: The reduction of some of the work procedures that the organization deems unnecessary, which in turn is reflected in the reduction of expenses and expenses is not justified, which contributes to reduce the total cost with the stability of profits achieved

- Increasing process: It is intended to add some materials and procedures with the ability to increase and improve the quality of products provided to customers

- Innovation process: Is one of the advanced characteristics of organizations in changing environments. It means transforming creative ideas into useful outcomes, or any new idea, practice, or expression for the individual who adopted. (Al Attar, 2010)

\section{Competitive Advantage:}

Achieving a competitive advantage has become a strategic goal that is sought by all the business organizations. It is sought in the aim of handling the intensive competition and overcoming challenges that are associated with the new economic climate. The company's ability to achieve a competitive advantage is an indicator for the 
company's ability to fulfill its customers' needs. It is also an indicator for the company's ability to provide its customers with the value they seek. Such a value may be represented in a highly quality level.

Scholars have provided several definitions for the expression (competitive advantage). For instance, Liu (2013, p. 15) defines competitive advantage as the product's attribute which allows the company to hold a high competitive position in the market. In other words, the competitive advantage is the product's attribute which allows the company to outperform its competitors in the market. Stevenson (2017, p. 15) suggests that as company aims to achieve a competitive advantage in the aim of fulfilling its customers' needs and desires. That is sought for attracting customers.

Evans et al. (2007, p. 32) suggest that the competitive advantage is an indicator for the company's ability to excel in financial and marketing aspects. However, achieving a competitive advantage requires meeting several requirements. For instance, it requires identifying the customers' needs and desires by the top management. It also requires identifying the way of fulfilling those needs and desires through the supply chain. It also requires delivering the concerned service or product on the right time to the customer. In addition, achieving a competitive advantage requires taking into consideration the operational capacity rate.

Johnson \& Scholes (2002, p. 55) suggest that the achievement of a competitive advantage is affected by two factors. The first factor is the company's ability to outperform its competitors. The second factor is the company's ability to excel in attracting customers. The company's ability to outperform its competitors depends on quality, price, time of delivery, after-sale services, and/ or innovation. It also depends on the company's ability to adapt itself quickly. As for the company's ability to excel in attracting customers, it depends on the company's ability to fulfill customers' needs and desires within local and global markets. Being able to attracting customers shall raise the customers' satisfaction level. It shall raise the company's prospects for growth and survival and the company's profits.

It should be noted that the company's competitive capabilities shall enable it to achieve competitive advantages. It shall also enable it to set effective strategies for competing with others. Having valuable resources shall provide the company with competitive capabilities. It shall also enable the company to achieve a competitive advantage.

Competitive advantages may include: the distinguished skills that employees have. Those skills enable the company's employees to outperform the competitors' employees. Such skills include the employees' ability to respond effectively. They also include the skills acquired while working within the company. A competitive advantage may include an effective information system that the company's has.

A competitive advantage must be examined well by the managers before informing others about it. The strengths of the competitive advantage must be identified and examined well. After that, the company must invest in the competitive advantage to improve its strength and reduce its weaknesses. That should be done to get a good competitive position, and outperform competitors. In addition, investing in the competitive advantage shall make it stuck in the head of customers and competitors.

Competitive advantages may be represented in a cost advantage or good offers. If the company is able to analyze the market well and set a good strategy for itself, customers shall identify their roles. That shall enable the company to increase its market share, gain more profits, and obtain benefits.

In order to achieve a competitive advantage, an organization must identify the existent and possible opportunities. That should be done through analyzing the competition. Such an analysis involves predicting the things that can attract customers at the time. Such an analysis also involves identifying the company's strengths and weaknesses in comparison to its competitors. After that, the scope and basis of the sought competitive advantage must be identified based on the fields of competition. After that, the competitive advantage shall be achieved.

When making a strategy for competition, the value provided to customers must be taken into consideration. That is because providing such a value shall make the company distinguished from other companies. When making such strategies, the company must provide its significant capabilities with much attention (Dube \& Renaghan, 1999, p. 23).

\section{The relationship between the application of the blue ocean strategy and the achievement of a competitive advantage:}

Many researchers found that there is a relationship between the application of the blue ocean strategy and the achievement of a competitive advantage. Ehsan (2013) found that the application of the blue ocean strategy plays a significant role in making organizational strategic changes. An analogy was made between the blue ocean strategy and the ocean which water is clear and blue. For instance, in the blue ocean strategy, the market place 
doesn't include competitors fighting for the same thing. That is similar to the ocean which water is clear and blue because it doesn't include bloody sharks fighting for the same pray. In contrast, an analogy was made between the red ocean strategy and the red ocean which water is bloody. For instance, in the red ocean strategy, the market place includes competitors fighting for the same thing. That's similar to an ocean which water is bloody because it includes sharks fighting for the same pray.

Jen-te (2010) suggests that the blue ocean strategy enables the company to make new brands, revive old brands, develop new industries, and make strategic alliance. It also enables the company to adjust the distribution channels, improve the perceived value and create a suitable environment.

Andrew et al. (2009) suggest that the blue ocean strategy makes significant changes in the company's strategic management. For instance, through the latter strategy, the value innovation principle is adopted by the company in the aim of achieving a competitive advantage. Through the latter strategy, the company aims to search for uncontested market places and create a new demand.

\section{The Study's Methodology}

In order to achieve the study's goals, a descriptive analytical approach was adopted. Through such an approach, the researchers collected information from respondents in the field. They also used two types of data. These types are presented below:

\section{First: Secondary data:}

This kind of data includes the data presented in documents, pamphlets, books, periodicals, journals, and previous studies. It also includes statistics and the data obtained through using the World Wide Web.

\section{Second: Primary data:}

This kind of data includes the data collected through using the questionnaire forms. The questionnaire consists from two parts. Through the first part, the researchers aimed to collect the respondents' occupational and demographic data (i.e. gender, age, academic qualification and years of experience). Through the second part, the researchers aimed to collect data about the independent variable (i.e. the blue ocean strategy) and the dependent variable (i.e. the achievement of a competitive advantage). The study's questionnaire was developed based on the questionnaire that was developed by Hashem \& Joudeh (2017).

The researchers of the present study adopted the five point Likert scale. The latter scale consists from the following rating points:

\begin{tabular}{llllll}
\hline & Strongly agree & Agree & Neutral & Disagree & $\begin{array}{l}\text { Strongly } \\
\text { disagree }\end{array}$ \\
\hline Score & 5 & 4 & 3 & 2 & 1 \\
\hline
\end{tabular}

\section{The Study's Population and Sample}

The study's population involves all the administrators who work in medium and high levels at the Jordanian telecommunication companies. These companies are: Zain Co., Umniah Co., and Orange Co. These companies form the backbone of telecommunications companies in the Jordanian market, accounting for their largest share of the telecommunications market in Jordan As for the sample; it consists from 100 administrators working at Jordanian telecommunications companies. The sample was chosen through adopting the convenience sampling method.

\section{The Reliability Test}

In order to measure the instrument's internal consistency, the values of Cronbach alpha coefficient were calculated. The overall rate of Cronbach alpha coefficient is $84.6 \%$. It is considered an accepted rate. (Malhotra, 2004)

\section{The Statistical Analysis Method}

The researchers used the statistical analysis methods that suit the nature of the study's variables. They also used the relevant descriptive statistical methods, which are: frequencies, arithmetic mean and standard deviation. The researchers also conducted a regression analysis.

\section{Results}

First: Characterizes of the Study's Sample

1)- Gender: 
Table 2. Distribution of the Study's Sample according to Gender

\begin{tabular}{lll}
\hline Gender & Frequency & Percentage \% \\
\hline Male & 58 & 58 \\
Female & 42 & 42 \\
Total & 100 & 100 \\
\hline
\end{tabular}

Based on table (2), it can be noticed that the number of males is greater than the number of females. That indicates that the number of male administrators is greater than the number of female administrators in the Jordanian telecommunication companies

2)- Age:

Table 3. Distribution of the Study's Sample according to Age

\begin{tabular}{lll}
\hline Age & Frequency & Percentage \% \\
\hline Less than 30 years & 29 & 29.0 \\
$30-40$ years & 44 & 44.0 \\
$41-50$ years & 18 & 18.0 \\
More than 50 years & 9 & 9.0 \\
Total & $\mathbf{1 0 0}$ & $\mathbf{1 0 0}$ \\
\hline
\end{tabular}

Based on table (3), it can be noticed that the ones whose age is between $30-40$ years represent the greatest percentage $(44 \%)$. It can be also noticed that the ones whose age is greater than 50 years represent the least percentage $(9 \%)$.

3)- Years of Experience

Table 4. Distribution of the Study's Sample according to Years of Experience

\begin{tabular}{lll}
\hline Years of Experience & Frequency & Percentage \% \\
\hline Less than 5 years & 38 & 38 \\
$5-10$ years & 17 & 17.0 \\
$11-15$ years & 39 & 39 \\
Greater than 15 years & 6 & 6.0 \\
Total & 100 & 100 \\
\hline
\end{tabular}

Based on table 4, it can be noticed that the ones who have $11-15$ years of experience represent greatest percentage (39\%). It can be noticed that the ones who have more than 15 years of experience represents the least percentage $(6 \%)$.

4)- The company

Table 5. Distribution of the Study's Sample according to the company

\begin{tabular}{lll}
\hline Company & Frequency & Percentage \% \\
\hline Zain Co. & 45 & 45 \\
Orange Co. & 32 & 32.0 \\
Umniah Co. & 23 & 23.0 \\
Total & 100 & 100 \\
\hline
\end{tabular}

Based on table (5), it can be noticed that the ones who work for Zain Co. represent the greatest percentage $(45 \%)$. It can be also noticed that the ones who work for Umniah and Orange companies represent the least percentage $(23 \%)$.

\section{Descriptive Analysis}

This part presents the descriptive results of the descriptive analysis. These results of the descriptive analysis are presented in table 6 below:

Table 6. Results of the descriptive analysis

\begin{tabular}{llll}
\hline No. & Statement & Mean & Std. Deviation \\
\hline 1 & The process of elimination & 4.5440 & .39295 \\
2 & The process of reduction & 4.5600 & .37118 \\
3 & The process of raising & 4.2780 & .48149 \\
4 & The process of innovation & 4.5267 & .50736 \\
5 & Competitive Advantage & 4.2440 & .55529 \\
\hline
\end{tabular}

Based on table (6), it can be noticed that the respondents' attitudes are positive. That is because the means are greater than 3 (average of the five rating points of the scale) ${ }^{1}$.

\footnotetext{
${ }^{1}$ The average of the five rating points of the scale was calculated through the following method:
} 


\section{Testing the Study's Hypotheses:}

A)- Testing the Main Hypothesis:

H0.1: The blue ocean strategy dimensions jointly don't have any statistically significant impact on the achievement of a competitive advantage

Table 7. Model Summary

\begin{tabular}{lllll}
\hline Model & R & R Square & Adjusted R Square & Std. Error of the Estimate \\
\hline 1 & $.957^{\mathrm{a}}$ & .917 & .913 & .16375 \\
\hline
\end{tabular}

a. Predictors: (Constant), Innovation, Reduction, Raising, Elimination

Table 8. ANOVA $^{\mathrm{a}}$

\begin{tabular}{lllllll}
\hline Model & & Sum of Squares & Df & Mean Square & F & Sig. \\
\hline \multirow{2}{*}{1} & Regression & 27.979 & 4 & 6.995 & 260.871 & $.000^{\mathrm{b}}$ \\
& Residual & 2.547 & 95 & .027 & & \\
& Total & 30.526 & 99 & & & \\
\hline
\end{tabular}

In order to test the main hypothesis, the researchers conducted the multiple regression analysis. It was found that $\mathrm{R}$ value is 0.957 . This value represents the strength of the correlation between the blue ocean strategy dimensions jointly and the achievement of a competitive advantage.

It was also found that the $\mathrm{R}$ square is 0.917 . That means that $91.7 \%$ of the changes in the competitive advantage are attributed to the blue ocean strategy dimensions jointly.

Table (8) presents the results of the analysis of variance (ANOVA). Based on the latter table, it can be noticed that the $\mathrm{F}$ value (260.871) is statistically significant at statistically significance level of (0.05). Thus, the blue ocean strategy dimensions jointly have a statistically significant impact on the achievement of a competitive advantage.

B)- Testing the first sub-hypothesis:

H0.1.1: The blue ocean strategy dimensions jointly do not have any statistically significant impact on the achievement of a competitive advantage in the Jordanian telecommunication companies

Table 9. Model Summary

\begin{tabular}{lllll}
\hline Model & R & R Square & Adjusted R Square & Std. Error of the Estimate \\
\hline 1 & $.908^{\mathrm{a}}$ & .824 & .822 & .23428 \\
\hline
\end{tabular}

a. Predictors: (Constant), Elimination

Table 10. ANOVA ${ }^{\mathrm{a}}$

\begin{tabular}{lllllll}
\hline Model & & Sum of Squares & df & Mean Square & F & Sig. \\
\hline \multirow{2}{*}{1} & Regression & 25.147 & 1 & 25.147 & 458.145 & $.000^{\mathrm{b}}$ \\
& Residual & 5.379 & 98 & .055 & & \\
\hline & Total & 30.526 & 99 & & & \\
\hline
\end{tabular}

Table 11. Coefficients ${ }^{\mathrm{a}}$

\begin{tabular}{|c|c|c|c|c|c|c|}
\hline \multirow[t]{2}{*}{ Model } & & \multicolumn{2}{|c|}{ Unstandardized Coefficients } & \multirow{2}{*}{$\begin{array}{l}\text { Standardized } \\
\text { Coefficients } \\
\text { Beta } \\
\end{array}$} & \multirow[t]{2}{*}{$\mathbf{t}$} & \multirow[t]{2}{*}{ Sig. } \\
\hline & & B & Std. Error & & & \\
\hline \multirow{2}{*}{1} & (Constant) & -1.584 & .273 & & -5.797 & .000 \\
\hline & Elimination & 1.283 & .060 & .908 & 21.404 & .000 \\
\hline
\end{tabular}

In order to test the first sub-hypothesis, the researchers conducted a linear regression analysis. It was found that $\mathrm{R}$ value is 0.908 . This value represents the strength of the correlation between the elimination process and the achievement of a competitive advantage.

It was also found that the R square is 0.824 . That means that $82.4 \%$ of the changes in the competitive advantage are attributed to the elimination process.

Table (11) presents the results of the analysis of variance (ANOVA). Based on the latter table, it can be noticed that the $F$ value (458.145) is statistically significant at statistically significance level of $(0.05)$. Thus, the elimination process - which is a blue ocean strategy dimension - has a statistically significant impact on the

$\frac{\text { The sum of the five rating points }}{\text { The number of the rating points }}=\frac{1+2+3+4+5}{5}=3$ 
achievement of a competitive advantage.

C)- Testing the Second Hypothesis

H0.1.2: The reduction process - which is a blue ocean strategy dimension - doesn't have any statistically significant impact on the achievement of a competitive advantage

Table 12. Model Summary

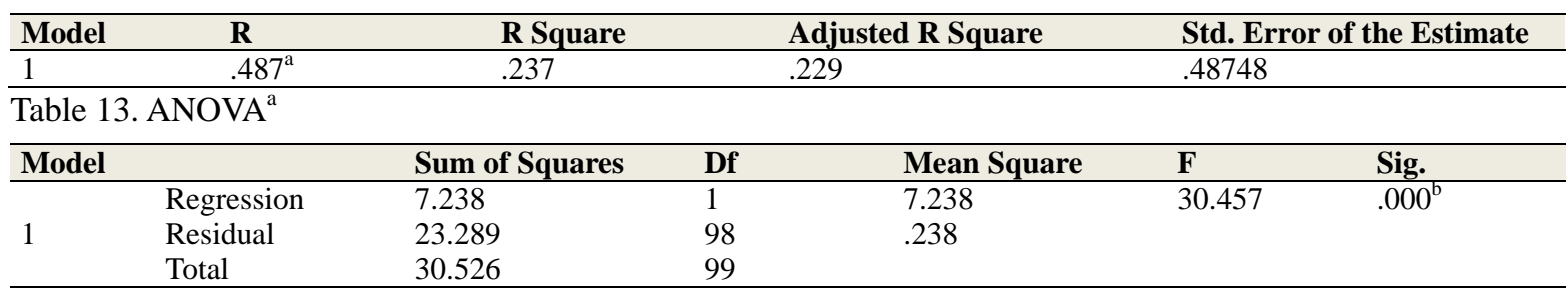

Table 14. Coefficients ${ }^{\mathrm{a}}$

\begin{tabular}{|c|c|c|c|c|c|c|}
\hline \multirow[t]{2}{*}{ Model } & & \multicolumn{2}{|c|}{ Unstandardized Coefficients } & \multirow{2}{*}{$\begin{array}{l}\text { Standardized } \\
\text { Coefficients } \\
\text { Beta } \\
\end{array}$} & \multirow[t]{2}{*}{$\mathbf{t}$} & \multirow[t]{2}{*}{ Sig. } \\
\hline & & B & Std. Error & & & \\
\hline \multirow{2}{*}{1} & (Constant) & .922 & .604 & & 1.527 & .130 \\
\hline & Reduction & .728 & .132 & .487 & 5.519 & .000 \\
\hline
\end{tabular}

In order to test the second sub-hypothesis, the researchers conducted a linear regression analysis. It was found that $R$ value is 0.487 . This value represents the strength of the correlation between the reduction process and the achievement of a competitive advantage.

It was also found that the $\mathrm{R}$ square is 0.237 . That means that $(23.7 \%)$ of the changes in the competitive advantage are attributed to the reduction process.

Table (13) presents the results of the analysis of variance (ANOVA). Based on the latter table, it can be noticed that the $\mathrm{F}$ value (30.457) is statistically significant at statistically significance level of $(0.05)$. Thus, the reduction process - which is a blue ocean strategy dimension - has a statistically significant impact on the achievement of a competitive advantage

D)- Testing the third sub-hypothesis:

H0.1.3: The increasing process - which is a blue ocean strategy dimension - doesn't have any statistically significant impact on the achievement of a competitive advantage.

Table 15. Model Summary

\begin{tabular}{|c|c|c|c|c|c|c|}
\hline Model & $\mathbf{R}$ & R Square & & Adjusted R Square & Std. Er & the Estimate \\
\hline 1 & $.738^{\mathrm{a}}$ & .545 & & .540 & .37656 & \\
\hline \multicolumn{7}{|c|}{ Table 16. ANOVA $^{\mathrm{a}}$} \\
\hline \multirow[t]{2}{*}{ Model } & & Sum of Squares & df & Mean Square & $\mathbf{F}$ & Sig. \\
\hline & Regression & 16.630 & 1 & 16.630 & 117.279 & $.000^{\mathrm{b}}$ \\
\hline \multirow[t]{2}{*}{1} & Residual & 13.896 & 98 & .142 & & \\
\hline & Total & 30.526 & 99 & & & \\
\hline
\end{tabular}

Table 17. Coefficients ${ }^{\mathrm{a}}$

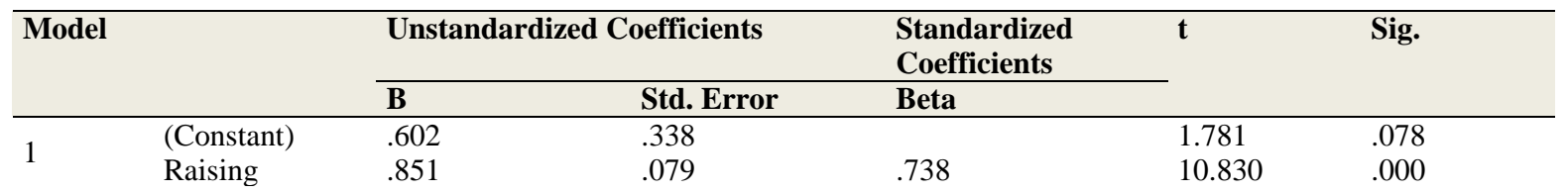

In order to test the third sub-hypothesis, the researchers conducted the linear regression analysis. It was found that $R$ value is 0 . 738. This value represents the strength of the correlation between the increasing process and the achievement of a competitive advantage.

It was also found that the R square is 0.545 . That means that $54.5 \%$ of the changes in the competitive advantage are attributed to the increasing process.

Table (16) presents the results of the analysis of variance (ANOVA). Based on the latter table, it can be noticed that the $F$ value (117.279) is statistically significant at statistically significance level of (0.05). Thus, the increasing process - which is a blue ocean strategy dimension - has a statistically significant impact on the achievement of a competitive advantage. 
E)- Testing the fourth sub-hypothesis

H0.1.4: The innovation process - which is a blue ocean strategy dimension - doesn't have any statistically significant impact on the achievement of a competitive advantage.

Table 18. Model Summary

\begin{tabular}{lllll}
\hline Model & R & R Square & Adjusted R Square & Std. Error of the Estimate \\
\hline 1 & $.811^{\mathrm{a}}$ & .657 & .654 & .32664 \\
\hline
\end{tabular}

a. Predictors: (Constant), Innovation

Table 19. ANOVAa

\begin{tabular}{lllllll}
\hline Model & & Sum of Squares & Df & Mean Square & F & Sig. \\
\hline \multirow{2}{*}{1} & Regression & 20.070 & 1 & 20.070 & 188.113 & $.000^{\mathrm{b}}$ \\
& Residual & 10.456 & 98 & .107 & & \\
& Total & 30.526 & 99 & & & \\
\hline
\end{tabular}

Table 20. Coefficientsa

\begin{tabular}{|c|c|c|c|c|c|c|}
\hline \multirow[t]{2}{*}{ Model } & & \multicolumn{2}{|c|}{ Unstandardized Coefficients } & \multirow{2}{*}{$\begin{array}{l}\text { Standardized } \\
\text { Coefficients } \\
\text { Beta } \\
\end{array}$} & \multirow[t]{2}{*}{$\mathbf{t}$} & \multirow[t]{2}{*}{ Sig. } \\
\hline & & B & Std. Error & & & \\
\hline \multirow{2}{*}{1} & (Constant) & .227 & .295 & & .770 & .443 \\
\hline & Innovation & .887 & .065 & .811 & 13.715 & .000 \\
\hline
\end{tabular}

In order to test the third sub-hypothesis, the researchers conducted the linear regression analysis. It was found that $\mathrm{R}$ value is 0 . 811 . This value represents the strength of the correlation between the innovation process and the achievement of a competitive advantage.

It was also found that the R square is 0.657 . That means that $65.7 \%$ of the changes in the competitive advantage are attributed to the innovation process.

Table (19) presents the results of the analysis of variance (ANOVA). Based on the latter table, it can be noticed that the $F$ value of (188.113) is statistically significant at statistically significance level of $(0.05)$. Thus, the innovation process - which is a blue ocean strategy dimension - has a statistically significant impact on the achievement of a competitive advantage.

\section{Results and Recommendations}

\section{Results:}

The researchers of the present study concluded the following:

1)- It was found that the blue ocean strategy dimensions are highly applied.

2)- The elimination process - which is a blue ocean strategy dimension - has a statistically significant impact on the achievement of a competitive advantage

3)- The decreasing process - which is a blue ocean strategy dimension - has a statistically significant impact on the achievement of a competitive advantage

4)- The increasing process - which is a blue ocean strategy dimension - has a statistically significant impact on the achievement of a competitive advantage.

5)- The innovation process - which is a blue ocean strategy dimension - has a statistically significant impact on the achievement of a competitive advantage.

The results of this study confirm the importance of the blue ocean strategy in business organizations, as it contributes to enhancing its competitive advantage and contributes to increasing its market share in the telecommunications market in Jordan

Also, the results of the present study are in agreement with the results of the studies that were reviewed. Such studies include the ones conducted by Ehsan (2013); Jen-te (2010); Andrew et al. (2009); and Hashem \& Joudeh (2017).

\section{Recommendations:}

In the light of the aforementioned results, the researchers recommend:

1) Providing customers with service guarantees by the Jordanian telecommunication companies. That is because providing service guarantees affects customers' decisions in terms of the company that they shall deal with.

2) Overcoming the obstacles that hinder the application of the blue ocean strategy by the senior management 
3) Utilizing the blue ocean strategy by companies and avoiding negative competition. The researchers also recommend making significant strategic changes in an ongoing manner. Such changes should be provided with support by the board of directors.

4) Innovating new things in an ongoing manner by the company. That should be done to ensure survival and keep competing with other companies.

5) Making policies in accordance with the customers' needs and desires.

6) Providing customers with services of high quality level. That shall raise the company's sales volume and profits.

7) Keeping records that include information about all the company's resources and business.

8) Future studies are recommended in the field of applying blue ocean strategies in other service sectors such as: Insurance, Hospitals, etc.

\section{Limitations of the Study}

This study aimed to identify the impact of applying the blue ocean strategy on the achievement of a competitive advantage in the Jordanian telecommunication companies from the view point of administrators working in medium and high levels only.

\section{References}

Al Attar, F. (2010). Blue Ocean Philosophy and its Role in Achieving Competitive Superiority : A study of the Opinions of Some Workers in Zain Telecommunication Company. Journal of University of Karbala, 8(3), $52-68$.

Andrew, B., André van, S., \& Roy, T. (2009). Blue Ocean versus Competitive Strategy: Theory and Evidence. University of Amsterdam, the Netherlands.

Armstrong, G., \& Kotler, P. (2007). Marketing: An introduction. Upper Saddle River, N.J: Pearson Prentice Hall.

Dube, L., \& Renaghan, L. (1999). Sustaining Competitive Advantage. The Cornell Hotel and Restaurant Administration Quarterly, 40(6), 27-33. https://doi.org/10.1177/001088049904000614

Ehsan, M. (2013). Blue Ocean Strategy As Revolution In The Field Of Strategic Management. Interdisciplinary Business Research, 4(9), 39-41.

Evans, J. R., Evans, J. R., \& Collier, D. A. (2007). Operations management: an integrated goods and services approach", Thomson/South-Western, U.S.A.

Hashem, T., \& Joudeh, J. (2017). The Extent of Implementation of the Blue Ocean Strategy in Jordanian Commercial Banks. International Journal of Current Advanced Research, 6(02), 1999-2004.

Jen-te, Y. (2012). "Identifying the attributes of blue ocean strategies in hospitality". International Journal of Contemporary Hospitality Management, 24(5), 701-720. https://doi.org/10.1108/09596111211237255

Johnson, G., \& Scholes, K. (2002). Exploring Corporate Strategy, New York: Prentice Hall.

Kim , W., chan \& Mauborgne, R. (2005). Blue Ocean strategy : How to creat uncontested market space and make the competition irrelevant, Harvard business school publishing corporation, printed in the U. S. A.

Kotler, P. (2008). Principles of Marketing , , pearson prentice- Hall , U.S.A. .

Liu, T. L. (2003). Organization Learning and Social Network Market Orientation: The Role of Resource-Based View Strategy in Gaining Dynamic, Capabilities Advantage", www.hicbusiness.org ,Working Paper, 1-9.

Malhotra, N. K. (2004). Marketing Research. New Jersey: Prentice Hall Mifflin Company

Stevenson, W. J. (2007). "Production / Operations Management", Von Hoffmann Press.

Yang, K. (2007). Voice of the customer : capture and analysis , prentice - Hall.

\section{Copyrights}

Copyright for this article is retained by the author(s), with first publication rights granted to the journal.

This is an open-access article distributed under the terms and conditions of the Creative Commons Attribution license (http://creativecommons.org/licenses/by/4.0/). 